\title{
D2-40 immunohistochemical analysis of pediatric vascular tumors reveals positivity in kaposiform hemangioendothelioma
}

\author{
Larisa V Debelenko¹, Antonio R Perez-Atayde ${ }^{1}$, John B Mulliken², Marilyn G Liang ${ }^{3}$, \\ Tonora H Archibald ${ }^{1}$ and Harry PW Kozakewich ${ }^{1}$ \\ ${ }^{1}$ Department of Pathology, Children's Hospital, Harvard Medical School, Boston, MA, USA; ${ }^{2}$ Department of \\ Surgery, Children's Hospital, Harvard Medical School, Boston, MA, USA and ${ }^{3}$ Department of Medicine, \\ Children's Hospital, Harvard Medical School, Boston, MA, USA
}

\begin{abstract}
Kaposiform hemangioendothelioma is a distinctive vascular neoplasm affecting predominantly children and neonates. In neonates it needs to be differentiated from common infantile hemangioma and other vascular lesions of infancy. Kaposiform hemangioendothelioma immunoreacts with vascular endothelial growth factor receptor 3, and partial lymphothelial differentiation of this lesion has been suggested. D2-40 has been recently proposed as a selective marker of lymphatic endothelium. We performed immunohistochemical analysis with the D2-40 antibody on $\mathbf{2 4}$ kaposiform hemangioendotheliomas and $\mathbf{4 8}$ other pediatric vascular lesions including common infantile hemangioma $(n=10)$, rapidly involuting congenital hemangioma $(n=10)$, noninvoluting congenital hemangioma $(n=9)$, verrucous hemangioma $(n=9)$, and pyogenic granuloma $(n=10)$ to define whether this marker can be applied in the diagnosis of vascular lesions of infancy. In all, 23 of 24 (96\%) kaposiform hemangioendotheliomas exhibited a distinct staining, while none of the other lesions immunoreacted with D2-40. D2-40 stained the neoplastic spindled cells and lymphatic channels adjacent to vascular lobules of kaposiform hemangioendothelioma. These findings support D2-40 as a new determinate marker for kaposiform hemangioendothelioma, useful in differentiating it from other vascular lesions of infancy and suggest lymphothelial differentiation of the neoplastic component of kaposiform hemangioendothelioma. Further studies are necessary to define the identity of the D2-40 antigen and to elucidate the biologic significance of its selective lymphothelial reactivity. Modern Pathology (2005) 18, 1454-1460. doi:10.1038/modpathol.3800444; published online 20 May 2005
\end{abstract}

Keywords: D2-40; immunohistochemistry; infantile hemangioma; kaposiform hemangioendothelioma

Kaposiform hemangioendothelioma is a distinctive vascular neoplasm affecting primarily children. The term was proposed in 1993 to delineate the entity from the infantile hemangioma. ${ }^{1}$ The lesion was originally described in deep soft tissues; however, it frequently affects dermis and subcutis, ${ }^{2-4}$ where it forms characteristic violaceous plaques. It is associated with profound thrombocytopenia (KasabachMerritt phenomenon) in more than a half of cases. ${ }^{3,5}$ Life-threatening hemorrhage is a major complication, and mortality is high, especially for large deeply located tumors. ${ }^{1,3,5-7}$ Although kaposiform hemangioendothelioma can stabilize over time, the

Correspondence: Dr LV Debelenko, MD, PhD, Department of Pathology, Children's Hospital, 300 Longwood Avenue, Boston, MA 02115, USA.

E-mail: Larisa.Debelenko@childrens.harvard.edu

Received 19 October 2004; revised and accepted 15 April 2005; published online 20 May 2005 tumor never totally regresses, even with successful pharmacologic therapy. ${ }^{8}$ The tumor is composed of irregular lobules of small malformed vascular channels with spindled cells; often there are abnormal adjacent lymphatics. ${ }^{1,3,5}$ The lesional cells immunoreact with common endothelial markers (CD31 and CD34) as well as with antibodies against the vascular endothelial growth factor receptor-3 (VEGFR-3), ${ }^{9,10}$ which preferentially stain lymphatic endothelium in adult tissues. ${ }^{11}$ It has been suggested that VEGFR-3 immunopositivity indicates partial lymphatic endothelial differentiation ${ }^{10}$ or, alternatively, vascular endothelial growth factor $\mathrm{C}$ production by the tumor cells that stimulates proliferation of adjacent lymphatics. ${ }^{5}$

D2-40 is a monoclonal antibody raised against dysgerminoma that binds a membrane sialoglycoprotein M2A. ${ }^{12}$ It has been observed that D2-40 selectively stains lymphatic endothelium in adult human tissue; this observation has been extended to 
finding D2-40 positivity in 'lymphangioma', Kaposi sarcoma and a subset of angiosarcoma, but not in benign tumors of blood vessels. ${ }^{13}$ Recently, D2-40 immunopositivity was reported in hobnail hemangioma, suggesting that this tumor is of lymphatic origin. ${ }^{14}$ Several studies employed D2-40 to evaluate lymphatics in nonvascular neoplastic and nonneoplastic lesions. ${ }^{15-17}$ Although the biologic significance of D2-40 immunoreactivity is unknown, it has been stated that the antibody reliably marks lymphatic but not blood vascular endothelium, ${ }^{13-17}$ and postulated that staining of lesional cells in a vascular neoplasm denotes lymphothelial differentiation. ${ }^{13,14}$

We immunostained kaposiform hemangioendotheliomas with D2-40 antibody to assess its diagnostic value and possibly elucidate the line of differentiation in this tumor. We also stained other pediatric vascular lesions to determine whether D240 would be helpful in differentiating kaposiform hemangioendothelioma, particularly from common infantile hemangioma and rapidly involuting and noninvoluting congenital hemangiomas, which can be difficult to histologically distinguish from kaposiform hemangioendothelioma in small biopsies.

\section{Materials and methods}

\section{Patients and Tumors}

We studied 72 vascular lesions from the files of the Department of Pathology of the Boston Children's Hospital. These included 64 surgical specimens, one autopsy specimen, and seven consultative cases. The patients' anonymity was preserved and the study was conducted in accord with the Children's Hospital Institutional Review Board policies.

The lesions included kaposiform hemangioendothelioma $(n=24)$, common infantile hemangioma $(n=10)$, rapidly involuting congenital hemangioma $(n=10)$, noninvoluting congenital hemangioma $(n=9)$, verrucous hemangioma $(n=9)$, and pyogenic granuloma $(n=10$, Table 1$)$. The slides were reviewed by two pathologists (LVD and HPWK) and the diagnoses were agreed upon using the classification recommended by the International Society for the Study of Vascular Anomalies ${ }^{18}$ as well as established histopathologic criteria. ${ }^{6}$

\section{D2-40 Immunohistochemical Analysis}

Four-micrometer sections of formalin-fixed, paraffin-embedded tumor tissue were incubated with D240 (diluted mouse monoclonal antibody, Signet Lab, Dedham, MA, USA) for $2 \mathrm{~h}$ at room temperature, after deparaffinization and antigen retrieval with acetate buffer, $\mathrm{pH} 9.5$ in a pressure cooker for $1.5 \mathrm{~min}$. Incubation with the secondary antibody and detection were performed using Supersensitive Link-Label immunohistochemistry detection system (Biogenex, San Ramon, CA, USA) in an automated processor Biogenex I 6000 as per the manufacturer. Both brown (diaminobenzidine) and violet (fuchsin) chromogens were used, the latter to facilitate the evaluation of staining in lesions with abundant hemosiderin.

\section{CD31, CD34 and Smooth Muscle Actin Staining}

Previously performed immunostains were available from the surgical pathology files in six of 24 cases of kaposiform hemangioendothelioma. A total of 10 additional kaposiform hemangioendotheliomas were immunostained with the above markers as part of the study. CD31 (PECAM), CD34, and smooth muscle actin (SMA) (1A4) mouse monoclonal antibodies were purchased from Biogenex, San Ramon, CA, USA and applied to deparaffinized sections, after antigen retrieval with trypsin, using instructions provided by manufacturer.

Positive (sections of normal tonsil) and negative (tumor sections without primary antibody incubation) controls were performed in each experiment. The immunostained sections were scored using the commonly accepted four-tier system based on visual impression ( 0 to $3+$ ). The staining intensity of lesional cells was compared to that of the lymphatics and blood vessels seen in the surrounding tissue.

\section{Results}

In the group of 24 kaposiform hemangioendotheliomas, patients' age ranged from 5 days to 54 years, with a median of 9 months; the male-to-female ratio was 1:1.2 (Table 2). The tumors were located predominantly in the skin and subcutis, exept for

Table 1 D2-40 immunostaining results in 72 pediatric vascular tumors

\begin{tabular}{lccc}
\hline Tumor type & Age range & Median age & \# Positive/ \# studied \\
\hline Kaposiform hemangiendothelioma & $5 \mathrm{da}-54 \mathrm{yr}$ & $9 \mathrm{mo}$ & $23 / 24$ \\
Common infantile hemangioma & $5 \mathrm{mo}-12 \mathrm{yr}$ & $3.5 \mathrm{yr}$ & $0 / 10$ \\
Rapidly involuting capillary & $4 \mathrm{da}-5 \mathrm{yr}$ & $6 \mathrm{mo}$ & $0 / 10$ \\
Non-involuting capillary hemangioma & $3-11 \mathrm{yr}$ & $4.5 \mathrm{yr}$ & $0 / 9$ \\
Verrucous hemangioma & $1-16 \mathrm{yr}$ & $4.5 \mathrm{yr}$ & $0 / 9$ \\
Pyogenic granuloma & $10 \mathrm{mo}-13 \mathrm{yr}$ & $6 \mathrm{yr}$ & $0 / 10$ \\
\hline
\end{tabular}

$\mathrm{da}=$ days $; \mathrm{mo}=$ months; $\mathrm{yr}=$ years.

${ }^{\mathrm{a}}$ Age at biopsy. 
Table 2 Clinical data and D2-40 immunostaining results in 24 Kaposiform hemangioendotheliomas

\begin{tabular}{|c|c|c|c|c|c|c|}
\hline Case \# & Age & Gender & Site & Previous treatment & $K M P$ & Staining intensity ( 0 to +++$)$ \\
\hline 1 & $1 \mathrm{mo}$ & $\mathrm{F}$ & Chest wall/neck & Unknown & $\mathrm{Y}$ & ++ \\
\hline 2 & $1 \mathrm{mo}$ & $\mathrm{F}$ & Shoulder/neck & $\mathrm{Y}$ & $\mathrm{Y}$ & + \\
\hline 3 & $10 \mathrm{yr}$ & $\mathrm{F}$ & Back & Y & Y & + \\
\hline 4 & $15 \mathrm{mo}$ & $\mathrm{F}$ & Neck & $\mathrm{Y}$ & $\mathrm{Y}$ & +++ \\
\hline 5 & $2 \mathrm{mo}$ & $\mathrm{M}$ & Scalp & $\mathrm{Y}$ & $\mathrm{Y}$ & + \\
\hline 6 & $8 \mathrm{mo}$ & $\mathrm{M}$ & Shoulder & Unknown & $\mathrm{Y}$ & + \\
\hline 7 & $5 \mathrm{da}$ & $\mathrm{F}$ & Thigh & $\mathrm{N}$ & $\mathrm{Y}$ & ++ \\
\hline 8 & $12 \mathrm{mo}$ & $\mathrm{F}$ & Chest wall & Unknown & $\mathrm{Y}$ & ++ \\
\hline 9 & $9 \mathrm{mo}$ & $\mathrm{F}$ & Retroperitoneum & Unknown & $\mathrm{Y}$ & +++ \\
\hline 10 & $9 \mathrm{mo}$ & $\mathrm{F}$ & Retroperitoneum & $\mathrm{Y}$ & $\mathrm{Y}$ & ++ \\
\hline 11 & $4 \mathrm{yr}$ & M & Shoulder & $\mathrm{Y}$ & $\mathrm{Y}$ & +++ \\
\hline 12 & $6 \mathrm{mo}$ & $\mathrm{F}$ & Buttock & $\mathrm{Y}$ & $\mathrm{Y}$ & +++ \\
\hline 13 & $9 \mathrm{yr}$ & $\mathrm{M}$ & Flank & $\mathrm{Y}$ & $\mathrm{Y}$ & + \\
\hline 14 & $54 \mathrm{yr}$ & $\mathrm{F}$ & Thigh & $\mathrm{Y}$ & $\mathrm{Y}$ & + \\
\hline 15 & $10 \mathrm{yr}$ & $\mathrm{F}$ & Chest & Unknown & $\mathrm{N}$ & +++ \\
\hline 16 & $11 \mathrm{mo}$ & $\mathrm{M}$ & Arm & $\mathrm{N}$ & $\mathrm{N}$ & + \\
\hline 17 & $2 \mathrm{mo}$ & $\mathrm{F}$ & Wrist & $\mathrm{N}$ & $\mathrm{N}$ & + \\
\hline 18 & $4 \mathrm{mo}$ & $\mathrm{M}$ & Cheek & $\mathrm{N}$ & $\mathrm{N}$ & +++ \\
\hline 19 & $1 \mathrm{mo}$ & $\mathrm{M}$ & Ear & $\mathrm{N}$ & $\mathrm{N}$ & +++ \\
\hline 20 & $14 \mathrm{mo}$ & $\mathrm{M}$ & Shoulder & $\mathrm{N}$ & $\mathrm{N}$ & +++ \\
\hline 21 & $10 \mathrm{da}$ & M & Abdominal wall/intestine & $\mathrm{N}$ & $\mathrm{Y}$ & 0 \\
\hline 22 & $2.5 \mathrm{mo}$ & $\mathrm{M}$ & Leg & $\mathrm{Y}$ & $\mathrm{N}$ & +++ \\
\hline 23 & $1.6 \mathrm{yr}$ & $\mathrm{F}$ & Arm & $\mathrm{N}$ & $\mathrm{N}$ & +++ \\
\hline 24 & $5 \mathrm{da}$ & $\mathrm{M}$ & Thigh & $\mathrm{N}$ & $\mathrm{N}$ & +++ \\
\hline
\end{tabular}

$\mathrm{KMP}=$ Kasabach-Merritt phenomenon; $\mathrm{da}=$ days; $\mathrm{mo}=$ months, $\mathrm{yr}=$ years; $\mathrm{M}=$ male; $\mathrm{F}=$ female; $\mathrm{Y}=$ yes; $\mathrm{N}=$ no.

cases nine and 10, where lesions involved the retroperitoneum, and case 21, where the lesion extended from the abdominal wall to the small intestine. Clinical information on histories of prior treatments were available in 19 cases. Ten of these 19 patients $(53 \%)$ were treated prior to biopsy by either alpha-interferon or a combination of alphainterferon and steroids, and four patients whose tumors showed no response (cases 1, 3, 11, 12) were additionally given vincristin and/or radiation and embolization. Seven of 24 lesions recurred, and in three recurrent cases two and more biopsies of the lesion were available for the study. Fifteen patients had Kasabach-Merritt phenomenon. Limited clinical follow-up data were available: two patients with deeply located lesions died (cases 9 and 21).

In all, 23 of 24 kaposiform hemangioendotheliomas $(96 \%)$ showed immunoreactivity with D2-40. The staining was concentrated at the peripheral part of vascular lobules where D2-40 highlighted neoplastic spindled cell that streamed between the lobules and circumscribed the 'glomeruloid' cores (Figures 1a, b and 2). The staining was also observed in an increased number of lymphatic channels that surrounded the lobules (Figure 1b). Common endothelial markers (CD31, CD34) showed diffuse staining of the vascular lobules, including the circumferential spindled cells at the periphery and small vascular channels in the center (Figure 1c). As has been described, ${ }^{5}$ the central portions of the lobules, or 'glomeruloid islands', in contrast to the cellular periphery, are composed of hematovascular channels with surrounding small SMA-positive cells, probably pericytes (Figure 1d). The character- istic D2-40 staining pattern was seen in all cases, including original biopsies, recurrent lesions, and lesions removed after therapy.

The staining was observed in $20-70 \%$ of the cellular component of the lesions, and $70-90 \%$ of the large spindled cells. The intensity of the staining varied (Table 2); however, this was probably mainly because the cases were collected over a 15-year period and processed under different conditions. The staining was pancytoplasmic and/or perinuclear in lesional spindled cells (Figure 2) and predominantly membranous in the endothelium of the adjacent lymphatic channels. The overall cellular distribution of the staining corresponded to the normal location of the M2A antigen (glycoprotein) on the cellular surface and within the Golgi complex. ${ }^{12}$ One of 24 lesions was negative; however, this might have been due to the small size of the biopsy containing only one tumor lobule.

None of the common infantile hemangiomas $(n=10)$, rapidly involuting hemangiomas $(n=10)$, noninvoluting hemangiomas $(n=9)$, verrucous hemangiomas $(n=9)$, and pyogenic granulomas $(n=10)$ stained for D2-40 under the same conditions (Table 1). Staining of normal lymphatics was observed in the surrounding dermis in all specimens.

\section{Discussion}

We found almost universal positivity of kaposiform hemangioendothelioma for D2-40, a feature reliably differentiating it from other vascular lesions of infancy, namely common infantile hemangioma, 

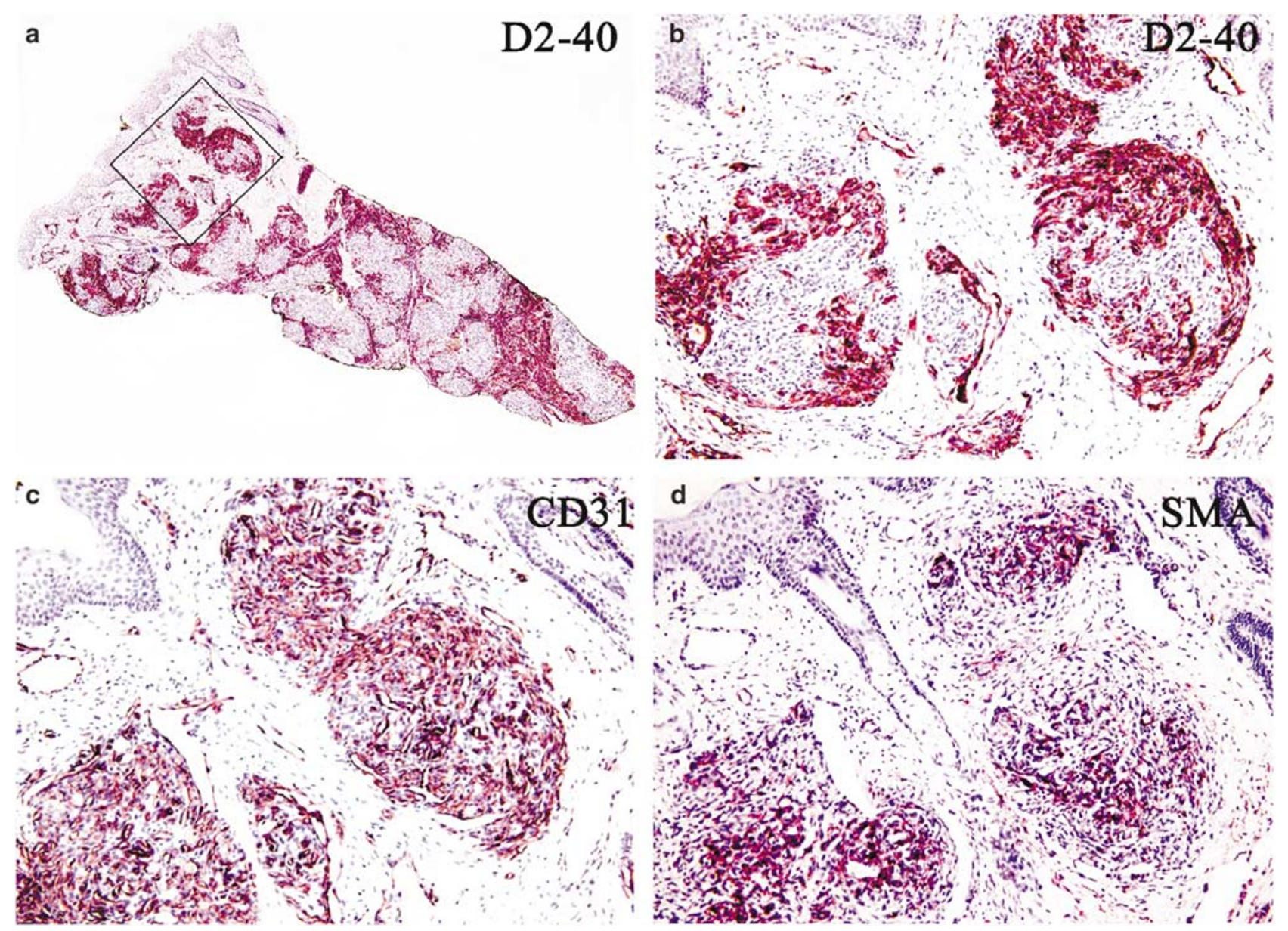

Figure 1 Comparison of D2-40, CD31 and SMA staining patterns in Kaposiform hamangioendothelioma (case 19). (a) D2-40 shows a distinct staining pattern which highlights the lobular 'glomeruloid' architecture of the lesion. (b) D2-40 stains neoplastic spindled cells at the periphery of the lobules and multiple lymphatic channels surrounding the lobules. (c) CD31 shows a diffuse staining of the lobules, including spindled cells at the periphery and small vascular channels in the center, (d) SMA shows increased staining in the center of the lobules due to the presence of small pericyte-like cells contributing to the so-call 'glomeruloid' core.

rapidly involuting and noninvoluting congenital hemangioma, verrucous hemangioma, and pyogenic granuloma. Kaposiform hemangioendothelioma, common infantile hemangioma, and rapidly involuting congenital hemangioma frequently have a similar clinical appearance in neonates, and the histopathologic diagnosis can be difficult in small biopsies. It has been previously shown that infantile hemangioma is positive for erythrocyte-type glucose transporter protein (GLUT1), ${ }^{19}$ whereas kaposiform hemangioendothelioma does not react with GLUT1. 5,19 D2-40, which also exhibits different reactivity in these two lesions, thus, can be used as an additional or alternative diagnostic marker.

Kaposiform hemangioendothelioma is the fifth known vascular lesion that is reportedly positive for D2-40: previously the immunopositivity was shown in lymphatic malformation (lymphangioma), Kaposi sarcoma, angiosarcoma, ${ }^{13}$ and hobnail hemangioma. ${ }^{14}$ It has been suggested that D2-40 immunoreactivity in these neoplasms denotes a lymphothelial origin. Lymphothelial differentiation of KHE has been ascribed because of its intimate association with thin-walled lymphatic vessels that encircle the tumor nodules. ${ }^{1,5}$ However, this association can be attributed to other factors: concomitant lymphatic malformation, lymphatic obstruction by the tumor, and/or lymphangiogenesis stimulated by the tumor. Kaposiform hemangioendothelioma has also been shown to be positive for VEGFR-3, a predominantly lymphatic marker; ${ }^{10}$ however, VEGFR-3 immunoreactivity is not exclusive for tumors of lymphatics. ${ }^{9}$

It has also been stated that the predominant neoplastic component of kaposiform hemangioendothelioma (spindled cells) recapitulates the phenotype of blood vascular endothelium (CD31 and CD34 positive), whereas the SMA-positive glomeruloid islands located within the vascular nodules represent zones of platelet trapping and blood destruction. ${ }^{5}$ Our D2-40 data suggest that the neoplastic component has a lymphothelial immunophenotype, and the observed differences in the staining of the periphery and the center of vascular 
1458
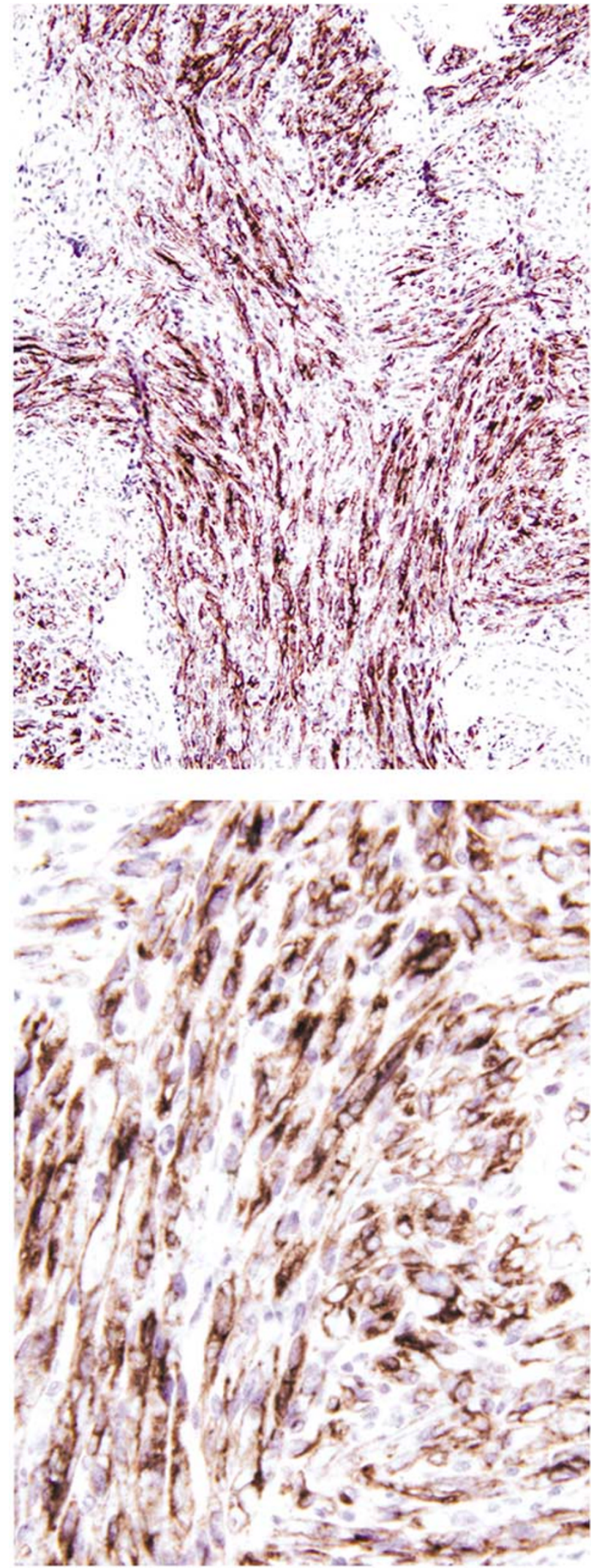

Figure 2 D2-40 Staining results in Kaposiform hemangioendothelioma (case 24). Positive neoplastic spindled cells surround negative 'glomeruloid' cores (top). The staining of neoplastic cells is diffuse cytoplasmic and perinuclear (bottom). lobules further highlight the architectural, and probably functional distinction between these two compartments. Dissecting the morphology and immunophenotypic characteristics of different components comprising a unique architecture of this lesion still does not clarify its pathogenesis; however, our data provide a support for lymphothelial differentiation of the neoplastic spindled cells, assuming that D2-40 is accurate in labeling the lymphatic endothelium.

The protein immunoreactive with D2-40 was purified from an ovarian cancer cell line by sequential affinity chromatography and analyzed by Western blotting and enzymatic digestion, the latter indicating the biochemical structure of an $\mathrm{O}$ linked sialoglycoprotein. ${ }^{12}$ The carbohydrate structure of the antigen recognized by D2-40 is common for mucin-type glycoproteins that are widely expressed in normal and tumor cells. ${ }^{20}$ Thus, although M2A was initially identified in fetal gonocytes, germ-cell tumors, and prepubertal Sertoli cells, ${ }^{21-23}$ it is also present in a number of human cancer cell lines, including osteosarcoma and transitional cell carcinoma. ${ }^{12}$ The broad application of D2-40 immunohistochemistry has established reactivity to multiple cell lineages and tumors such as mesothelioma, ovarian serous carcinoma, schwannoma, meningioma, synovial sarcoma, gastro-intestinal stromal tumor, leiomyosarcoma and others. ${ }^{24-26}$ It is unknown whether D2-40 immunoreactivity in a wide spectrum of normal and neoplastic cells is due to a single protein expressed in these various tissues or results from a crossreactivity with multiple surface glycoproteins sharing the D2-40-recognized epitope defined by the common carbohydrate core. It is also unknown whether D2-40 reacts with the same or different antigens in normal lymphatics and in vascular tumor cells.

The selective D2-40 immunoreactivity of lymphatic, but not blood vascular endothelium was discovered by observation of normal tissues. ${ }^{13,24}$ Although the data are consistent, it should be noted that no systematic study involving all organs and tissue types, including embryonal and fetal, has been conducted. It is also known that none of the previously studied lymphatic markers (VEGFR-3, podoplanin, homeobox gene product Prox-1, hyaluronan receptor LYVE-1) are specific for lymphatic vasculature. $^{27}$ Although some markers are fairly specific for lymphothelium, they exhibit different expression patterns during prenatal development and the respective immunopositivity does not necessarily indicate the lymphothelial origin of a vascular tumor. For example, VEGFR-3 selectively stains normal lymphatics in adult tissues; $;^{28,29}$ however, it is expressed in both lymphatic and blood vessels in the early embryonal period. ${ }^{28}$ Furthermore, both blood vessel and lymphatic vascular tumors immunoreact with the VEGFR-3 antibody. ${ }^{9}$

Another predominantly lymphothelial marker, LYVE-1 has been shown to stain endothelium of 
lymphatic vessels, as well as hepatic and splenic sinusoids. ${ }^{30}$ Immunoreactivity with LYVE-1 has also been demonstrated in angiosarcoma, Kaposi sarcoma, ${ }^{31}$ and in infantile hemangioma in the proliferative stage. ${ }^{32}$ The cells of proliferating infantile hemangioma are characterized by an immature immunophenotype similar to that observed in the cardinal vein in the early embryonal period (CD31 ${ }^{+}$, $\mathrm{CD}^{+} 4^{+}, \mathrm{LYVE}_{-1}{ }^{+}, \mathrm{GLUT}^{+}{ }^{+}$, Prox-1${ }^{-}$). These findings led to a hypothesis of an arrested vascular development in infantile hemangioma. ${ }^{32}$ Our data indicate that infantile hemangioma is negative for D2-40, including lesions in the proliferative stage $(n=5)$. This suggests that the expression of a yet unidentified surface molecule, recognized by D2-40, is probably a late event in lymphothelial development. We also found (data not shown) that LYVE-1 stains kaposiform hemangioendothelioma, similar to D2-40. This finding additionally supports the lymphothelial differentiation of the kaposiform hamangioendothelioma and demonstrates the complexity of interplay of different factors in endothelial differentiation and in vascular tumorigenesis.

In conclusion, we have shown that kaposiform hemangioendothelioma, in contrast to other pediatric vascular lesions, is positive for D2-40 by conventional immunohistochemistry. The data highlight D2-40 as an extremely useful marker of kaposiform hemangioendothelioma. Further studies are necessary to define the identity and functions of the D2-40immunoreacting surface antigen (antigens) to confirm that its expression in kaposiform hemangioendothelioma signifies a recapitulation of lymphatic differentiation and not merely an epiphenomenon common to neoplastic cells of different lineages.

\section{References}

1 Zukerberg LR, Nickoloff BJ, Weiss SW. Kaposiform hemangioendothelioma of infancy and childhood. An aggressive neoplasm associated with Kasabach-Merritt syndrome and lymphangiomatosis. Am J Surg Pathol 1993;17:321-328.

2 Vin-Christian K, McCalmont TH, Frieden IJ. Kaposiform hemangioendothelioma: an aggressive, locally invasive vascular tumor that can mimic hemangioma of infancy. Arch Dermatol 1997;133:1573-1578.

3 Sarkar M, Mulliken JB, Kozakewich HP, et al. Thrombocytopenic coagulopathy (Kasabach-Merritt phenomenon) is associated with Kaposiform hemangioendothelioma and not with common infantile hemangioma. Plast Reconstr Surg 1997;100:13771386.

4 Mac-Moune Lai F, To KF, Choi PC, et al. Kaposiform hemangioendothelioma: five patients with cutaneous lesion and long follow-up. Mod Pathol 2001;14: 1087-1092.

5 Lyons LL, North PE, Mac-Moune Lai F, et al. Kaposiform hemangioendothelioma: a study of 33 cases emphasizing its pathologic, immunophenotypic, and biologic uniqueness from juvenile hemangioma. Am J Surg Pathol 2004;28:559-568.
6 Weiss SW. Hamangioendothelioma: vascular tumors of intermediate malignancy. In: Strauss M (ed). Enzinger and Weiss's Soft Tissue Tumors, 4th edn. MosbyHarcourt Brace: Philadelphia, PA, 2001, pp 891-915.

7 Ezekowitz R, Mulliken J, Folkman J. Interferon alfa 2a therapy for life-threatening hemangiomas of infancy. New Engl J Med 1992;326:1456-1463.

8 Enjolras O, Mulliken JB, Wassef M, et al. Residual lesions after Kasabach-Merritt phenomenon in 41 patients. J Am Acad Dermatol 2000;42:225-235.

9 Partanen TA, Alitalo K, Miettinen M. Lack of lymphatic vascular specificity of vascular endothelial growth factor receptor 3 in 185 vascular tumors. Cancer 1999; 86:2406-2412.

10 Folpe AL, Veikkola $\mathrm{T}$, Valtola $\mathrm{R}$, et al. Vascular endothelial growth factor receptor-3 (VEGFR-3): a marker of vascular tumors with presumed lymphatic differentiation, including Kaposi's sarcoma, kaposiform and Dabska-type hemangioendotheliomas, and a subset of angiosarcomas. Mod Pathol 2000;13: 180-185.

11 Enholm B, Jussila L, Karkkainen M, et al. Vascular endothelial growth factor-C; a growth factor for lymphatic and blood vascular endothelial cells. Trends Cardiovasc Med 1998;8:292-297.

12 Marks A, Sutherland DR, Bailey D, et al. Characterization and distribution of an oncofetal antigen (M2A antigen) expressed on testicular germ cell tumours. Br J Cancer 1999;80:569-578.

13 Kahn HJ, Bailey D, Marks A. Monoclonal antibody D2-40, a new marker of lymphatic endothelium, reacts with Kaposi's sarcoma and a subset of angiosarcomas. Mod Pathol 2002;15:434-440.

14 Franke FE, Steger K, Marks A, et al. Hobnail hemangiomas (targetoid hemosiderotic hemangiomas) are true lymphangiomas. J Cutan Pathol 2004;31:362-367.

15 Kahn HJ, Marks A. A new monoclonal antibody, D2-40, for detection of lymphatic invasion in primary tumors. Lab Invest 2002;82:1255-1257.

16 Fogt F, Pascha TL, Zhang PJ, et al. Proliferation of D2-40-expressing intestinal lymphatic vessels in the lamina propria in inflammatory bowel disease. Int J Mol Med 2004;3:211-214.

17 Dumoff KL, Chu C, Xu X, et al. Low D2-40 immunoreactivity correlates with lymphatic invasion and nodal metastasis in early-stage squamous cell carcinoma of the uterine cervix. Mod Pathol 2005;18:97-104.

18 Enjolras O, Mulliken JB. Vascular tumors and vascular malformations (new issues). Adv Dermatol 1998;13: 375-422.

19 North PE, Waner M, Mizeracki A, et al. GLUT1: a newly discovered immunohistochemical marker for juvenile hemangiomas. Hum Pathol 2000;31:11-22.

20 Carraway KL, Hull SR. O-glycosylation pathway for mucin-type glycoproteins. BioEssays 1989;10: 117-121.

21 Bailey D, Baumal R, Law J, et al. Production of a monoclonal antibody specific for seminomas and dysgerminomas. Proc Natl Acad Sci USA 1986;83: 5291-5295.

22 Baumal R, Bailey D, Giwercman A, et al. A novel maturation marker for human Sertoli cells. J Androl 1989;12:354-359.

23 Jorgensen N, Rajpert-De Meyts E, Graem N, et al. Expression of immunohistochemical markers for testicular carcinoma in situ by normal human fetal germ cells. Lab Invest 1995;72:223-231. 
24 Kaiserling E. Immunohistochemical identification of lymph vessels with D2-40 in diagnostic pathology. Pathologe 2004;25:362-374 (German).

25 Bellucci KSW, Lee CCR, Oasha TL, et al. D2-40 immunoreactivity in spindle cell tumors, a specific lymphatic endothelial marker? Mod Pathol 2004; 17(Suppl):10A.

26 Chu AY, Litzky LA, Pasha TL, et al. Utility of D2-40, a novel mesothelial marker, in the diagnosis of malignant mesothelioma. Mod Pathol 2005;18:105-110.

27 Podgrabinska S, Braun P, Velasco P, et al. Molecular characterization of lymphatic endothelial cells. Proc Natl Acad Sci USA 2002;99:16069-16074.

28 Kaipainen A, Korhonen J, Mustonen T, et al. Expression of the fms-like tyrosine kinase 4 gene becomes restricted to lymphatic endothelium during development. Proc Natl Acad Sci USA 1995;92:3566-3570.
29 Jussila L, Valtola R, Partanen TA, et al. Lymphatic endothelium and Kaposi's sarcoma spindle cells detected by antibodies against the vascular endothelial growth factor receptor-3. Canc Res 1998;58:1599-1604.

30 Mouta Carreira C, Nasser SM, di Tomaso E, et al. LYVE1 is not restricted to the lymph vessels: expression in normal liver blood sinusoids and down-regulation in human liver cancer and cirrhosis. Canc Res 2001;61:8079-8084.

$31 \mathrm{Xu} \mathrm{H}$, Edwards JR, Espinosa O, et al. Expression of a lymphatic endothelial cell marker in benign and malignant vascular tumors. Hum Pathol 2004;35: 857-861.

32 Dadras SS, North PE, Bertoncini J, et al. Infantile hemangiomas are arrested in an early developmental vascular differentiation state. Mod Pathol 2004;17: 1068-1079. 